\title{
Analysis and evaluation of the effect of vibrations on historical buildings
}

\author{
Shota Urushadze $^{1, *}$ and Miroš Pirner ${ }^{1}$ \\ ${ }^{1}$ Institute of Theoretical and Applied Mechanics, AS CR, v. v. i., Prosecká 76, Prague, 19000 , \\ Czech Republic
}

\begin{abstract}
Continued exposure of human induced vibrations contributes to the degradation of materials and joints, causing the initiation of cracks or the growth of existing ones, such that they may endanger the structure. Loads, which an undamaged structure could safely resist, can be critical if repeated numerous times. This risk is present in various types of historical buildings, and is influenced by changes in vibration magnitude, by the distance from their source, and by the quality of the building's maintenance. Good maintenance, which includes regular inspections, allows early detection of any emerging damage and its subsequent repair. This article describes the methods and results of the measurement of dynamic response to road traffic and other types of technical seismicity in four historic buildings. The goal of this paper is to present some examples of analysis and evaluation of the effects of such human activity.
\end{abstract}

\section{Introduction}

Preservation and assessment of old masonry structures is a topic of increasing interest, evoked by the collapses of the city tower in Pavia, Italy [4, 5]. Extensive research is being carried out by the UK Transport and Road Research Laboratory [13], where building damage resulting from vibrations generated by traffic is studied. There are often cases where it is difficult to determine the level of vibration caused by traffic that can damage a structure, and the measured values do not clearly reveal their cause [9,11]. In general, the research involves theoretical and experimental analysis as well as other tasks including terrain observations, non-destructive testing, laboratory testing on models, finite element analysis, and theoretical studies. The acceptable experimental response can be assessed and evaluated according to the international standard [17], as in publications [10,12]. This standard allows for an estimation of the level of safety for buildings exposed to the effects of technical seismicity, and is based on the measured velocities of vibrations in the foundations of the building being researched.

The level of vibration significantly depends on soil type and stratification, for example in soil with reduced stiffness or dampened soil, vibration levels increase. In areas underlain by a soft silty clay with a depth of 7 to 15 meters, vibrations induced by traffic reach even greater values [11]. In literature there are known workplaces dealing with the effects of technical seismicity, and numerous applications of modal analysis of civil structures such as bridges

* Corresponding author: urushadze@itam.cas.cz 
and tall buildings, but only exceptionally, the effects on historical buildings which have a complex structure. An analysis of the dynamic effects on different types of buildings and their constructions can be found in $[1,3,6-8,14,15]$.

\section{Dynamic responses of masonry built structures to road traffic}

There are many sources of technical seismicity, but currently, industrial blasting, machine excitations, and traffic are considered the most important sources.

Shock initiation mechanisms are different for various sources, but in principle, waves always propagate from a source. These waves affect objects, people and devices. This spreads vibration in the ground, which is very diverse and non-linear, and which also has only complex exact theoretical solutions. In general, a homogeneous and isotropic medium is considered, to which the continuum theory can be applied.

Several researchers consistently dealt with the effects of vibrations caused by moving vehicles on masonry buildings, in particular historical ones. Traffic vibrations were measured in several locations. To reach a theoretical solution, they relied on simplifying assumptions. The main objective data for a proper selection of the calculation method for masonry buildings exposed to loads from dynamic forces and for the identification of certain patterns of responses to dynamic loads can therefore only be obtained from the experimental measurement of vibrations of built structures.

\section{Statistical evaluation of measurement results}

The movements of the structural foundations induced by moving vehicles appear as responses of the subsoil top layer. Waves similar to the ones created during an earthquake spread from the points where vehicles touch the road. However, during an earthquake, surface waves are induced by deep seismic waves that have reached the earth's surface from the source (epicentre). These surface seismic waves are slower and longer than deeper ones. The amplitudes of these waves are usually higher than the amplitudes of deep waves. The spreading zone of deep waves is rather small and is located in the immediate vicinity of the epicentre. As a result, the surface waves reach longer distances from the epicentre.

When comparing the seismic surface vibration characteristics with vibrations induced by traffic, it is obvious that the frequencies, amplitudes, and durations are different in both cases. The vibrations induced by traffic occur in short periods. On the main transport routes in cities, these conditions last eight or more hours every day and are almost continuous. The vibration acceleration is substantial. During earthquakes, the effects are only short and rare, whereas traffic effects are long-term and recurrent.

The surface waves cause vibrations of the subsoil in both the vertical and horizontal directions. With increasing distance from the points where vehicles touch a road surface, the horizontal component of the surface vibration amplitude prevails over the vertical component, and as a result, the most dangerous impacts on most structures are from the horizontal vibration of the subsoil related to the surface wave passing through.

Subsoil vibration induced by traffic is quite complicated due to a range of factors related to reflections, fractures, damping, and interactions between various waves spreading at different velocities and at different frequencies: the vibrations do not correspond to a deterministic solution.

In the 1971s Bat'a processed measurement results statistically [2]. Here is an overview of the results of certain processed measurement records. Forced oscillations were investigated from various vehicles at St. Tomas in the Lesser Town of Prague. Graphical representation 
of a group distribution of frequencies in a histogram and a distribution function. The best match was obtained using the Pearson type III distribution see Fig. 1.

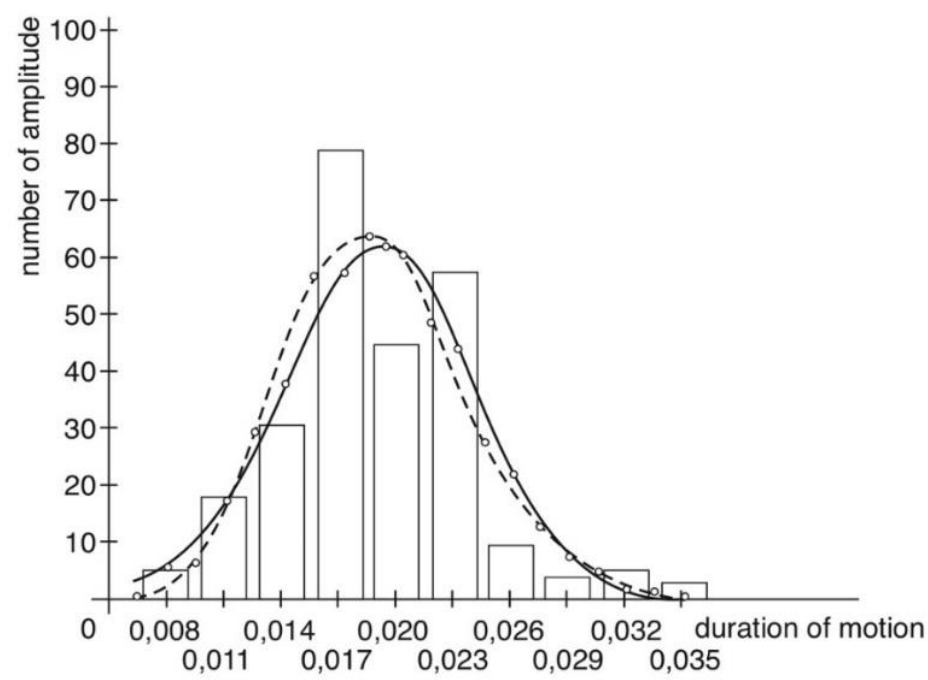

Fig. 1. A bar graph of horizontal vibrations spreading from the site as old tram cars pass by. The theoretical normal distribution curve and the Pearson type III distribution curve.

The basic characteristics of the observed static files that were calculated provide information on the diameter $\bar{M}$, variance $\bar{D}$, variation coefficient $V$ and inclination $\alpha$.

Note: The variation coefficient is defined as a ratio between the $\sqrt{\bar{D}}$, and $\bar{M}$, i.e.

$$
V=\frac{\sqrt{\bar{D}}}{\bar{M}}
$$

\section{Roman basilica of St Wenceslas in Stara Boleslav}

The Baroque reconstruction of this building was completed in 1745. This is a three-nave building with a central nave and two separated aisles (see Fig. 2). The central nave is vaulted by a barrel vault with lunettes; the clearance between the vault imposts is $9.30 \mathrm{~m}$, the axial distance between the vault imposts is $5.0 \mathrm{~m}$, and the height of the voussoir arches is $4.0 \mathrm{~m}$. The vault thickness at the peak is $230 \mathrm{~mm}$ including the plaster. The clearance of the aisle is $13.63 \mathrm{~m}$. The vault is disturbed along the length of the aisle by a continuous crack along the top. Some lunettes are also damaged by cracks. The aisles are also vaulted with barrel vaults with lunettes; the clearance between the vault imposts is $3.90 \mathrm{~m}$ for the northern aisle and $4.80 \mathrm{~m}$ for the southern aisle; the axial distance between the vault imposts is $5.0 \mathrm{~m}$. The height of the voussoir arch is $2.30 \mathrm{~m}$ for the northern aisle, $2.36 \mathrm{~m}$ for the southern aisle, and the vault thicknesses at the peaks are $250 \mathrm{~mm}$ including the plaster. The clearance is $6.68 \mathrm{~m}$ for the northern aisle and $7.16 \mathrm{~m}$ for the southern aisle. There are buttresses on the outside peripheral walls in the positions of the vault imposts of both aisles. The vault ceiling does not show any apparent defects, neither do the peripheral walls of the central nave and the aisles. According to available information, the building was constructed on layers of river gravel. 

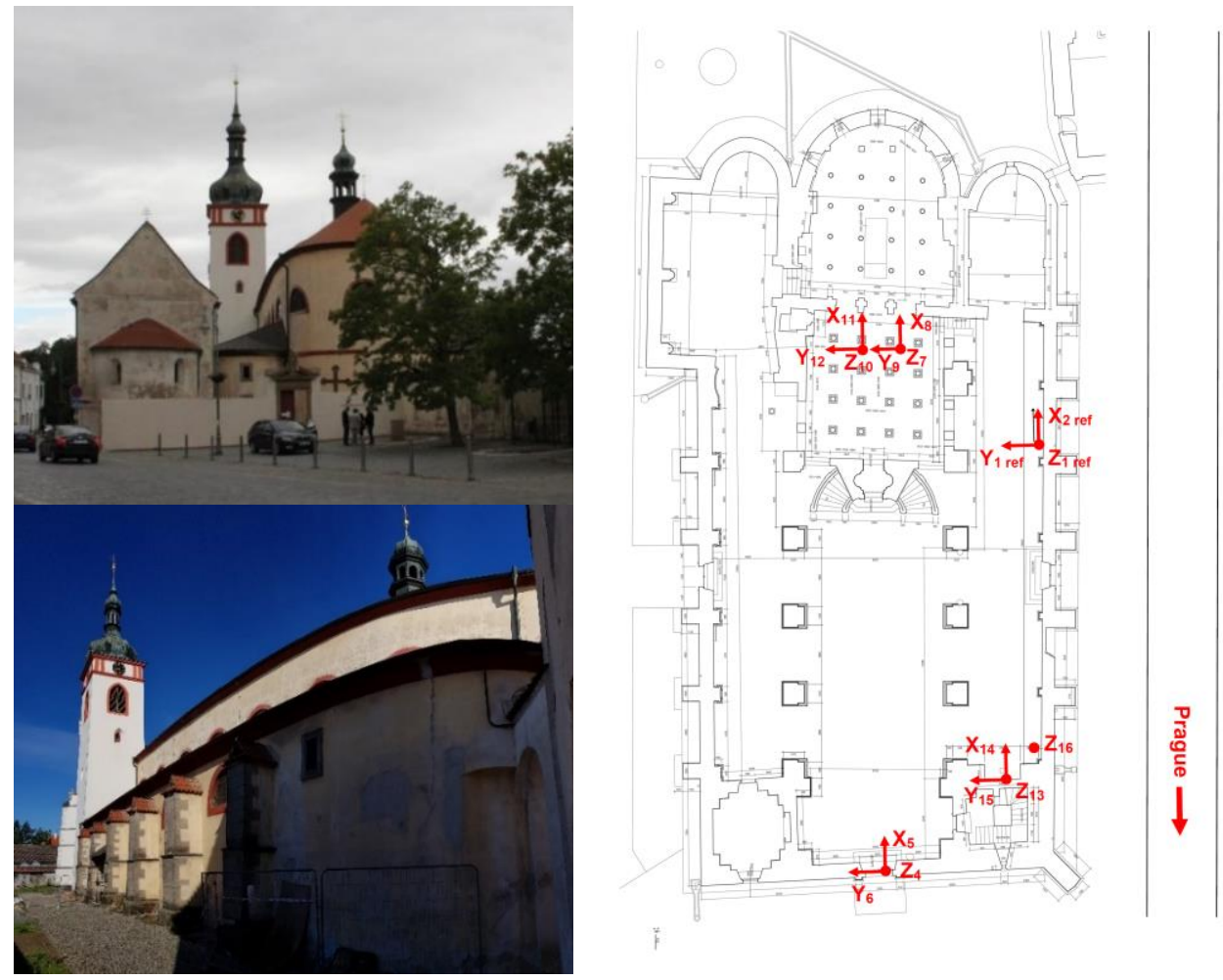

Fig. 2. Basilica st. Wenceslav in Stara Boleslav and plan of the accelerometers setup.

\section{The Basilica of the Assumption of the Virgin Mary}

The sacred buildings include the Basilica of the Assumption of the Virgin Mary with a cloister on east side (see Fig. 3). We mention this basilica as an example of our research. The church is surrounded with a terrace and access staircases. The terrace also provides access to the cloister.

The single-nave church has lateral chapels between pillars that support the masonry above the vaults, the lateral chapels, and the vault in the main nave. The church layout is rectangular with a semi-circular apse along the longitudinal axis on the east end. The external width of the layout is $22.2 \mathrm{~m}$, the length including the apse is $48.0 \mathrm{~m}$, the height of the main nave is $22.0 \mathrm{~m}$, and the width of the nave is $13.8 \mathrm{~m}$. The barrel vault above the main nave has reinforcing vault strips $1.3 \mathrm{~m}$ wide and $7.9 \mathrm{~m}$ apart; its height is $6.9 \mathrm{~m}$, and the clearance of the vault abutments is $13.8 \mathrm{~m}$. The thickness of the vault, including the plaster, is about 200 $\mathrm{mm}$, and the face of the reinforcing vault strips under the face of the barrel vault is $300 \mathrm{~mm}$ thick. The abutments of the barrel vault lean against the perimeter brick masonry, which is $1000 \mathrm{~mm}$ wide in the area of the vault abutment. Under the level of the pilaster heads (the upper edge of the heads is $15.15 \mathrm{~m}$ above the church floor), the masonry widens to $1600 \mathrm{~mm}$ and rests on the barrel vaults of the lateral chapels, which create an arcade along both sides of the church's inner space. These vaults form an apex $12.4 \mathrm{~m}$ above the church floor, their depth from the inner face of the perimeter masonry in the main nave towards the side frontage is $3.1 \mathrm{~m}$, and they lean against pillars $1350 \mathrm{~mm}$ wide with axial distances of $7.9 \mathrm{~m}$.

The vault of the main nave and the presbytery is damaged by a longitudinal crack in the apex of the vault along the entire length of the interior space; moreover, the vault of the main 
nave is damaged by cracks running in the same direction in the funicular arches of the barrel vault. Cracks have also damaged the vaults of the longitudinal passages above the vaults of the lateral chapels. These cracks are perpendicular to the longitudinal axis of the church and are located in the oriels of the main nave. Cracks perpendicular to the church's longitudinal axis have also damaged the barrel vaults of the lateral chapels.
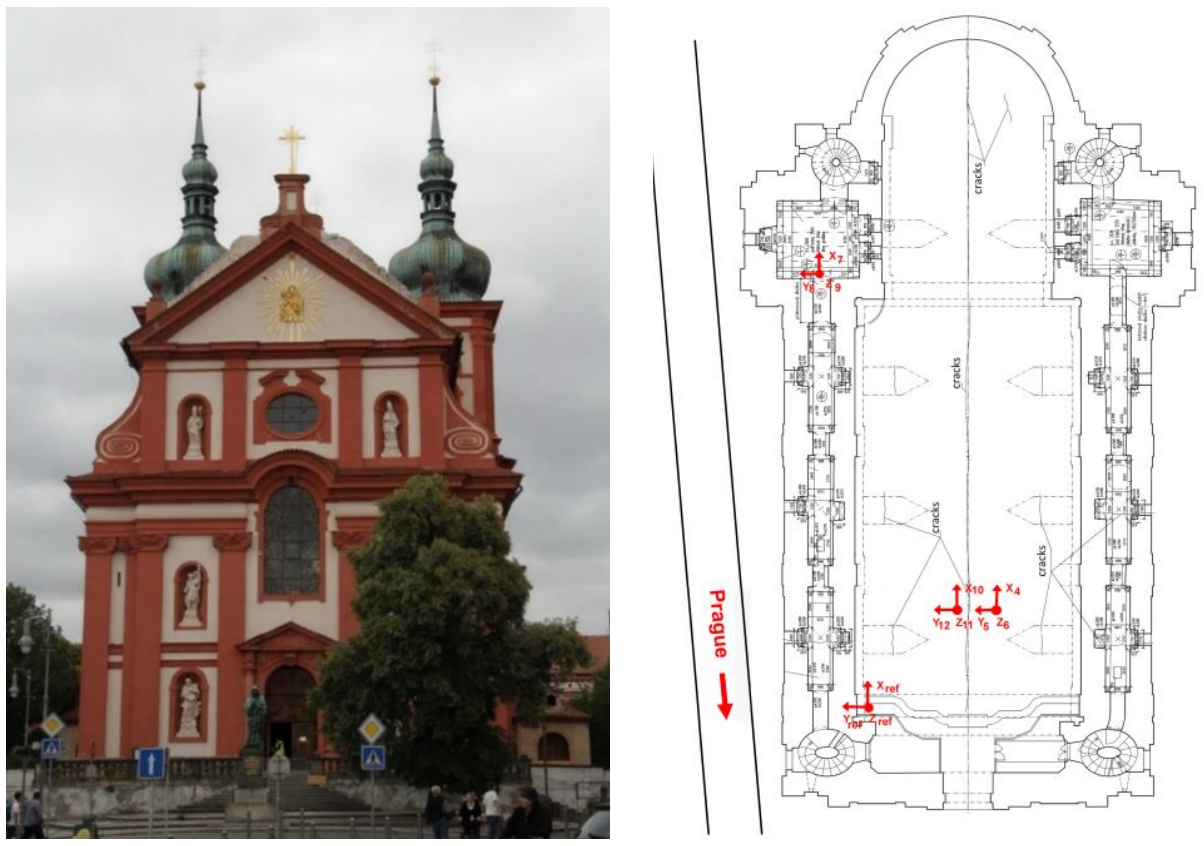

Fig. 3. The front view of the Basilica of the Assumption of the Virgin Mary and plan of the accelerometers setup.

\section{Measurement of the dynamic response}

Vibrations were measured using Wilcoxon Research Model 731A accelerometers with high sensitivities of $10 \mathrm{~V} / \mathrm{g}$ and noise characteristics of $0.5 \mu \mathrm{g}$ RMS. The accelerometer reliably measures at temperatures of $-10{ }^{\circ} \mathrm{C}$ to $+65^{\circ} \mathrm{C}$. It has an integrated low-pass filter, which can eliminate high frequencies caused by changes in the acoustic pressure of the surrounding area. The accelerometers are connected to a Dewetron DEWE43 sixteen-channel computer with a 24-bit AD converter and simultaneous sampling at $200 \mathrm{kS} / \mathrm{s}$. The input voltage can be adjusted to one of four ranges: $\pm 10 \mathrm{~V}, \pm 1 \mathrm{~V}, \pm 100 \mathrm{mV}$, and $\pm 10 \mathrm{mV}$.

The data was evaluated in the MATLAB programming environment. The sampling frequency $f_{s}=5000 \mathrm{~Hz}$ was used. The duration of each time record was 60 minutes.

The authors present here two selected cases of the analysis of historical structures, that have been analyzed from the perspective of dynamic loading. Thus, the work can be classified as a multiple-case study and may help engineers working in the field of historical structures gain information about their dynamic response.

The dynamic response was measured at a reference point and other points on the $\mathrm{X}, \mathrm{Y}$, and $\mathrm{Z}$ axes. From the one-hour records, 10- to 30-second sections were selected and processed with a computer for evaluation of the final maximum effective vibration velocity, as it is apparent in Tables 1 and 2. Fig. 4 and 5 shows examples of the recorded accelerations in the vertical and horizontal directions and corresponding Fourier spectra (FFT) for time histories at the reference point. 
Table 1. Basilica of St Wenceslas.

\begin{tabular}{|c|c|c|c|c|c|}
\hline Measurement & load & ride direction & $\begin{array}{c}\text { Dominant } \\
\text { frequency }[\mathbf{H z}]\end{array}$ & $\begin{array}{c}\text { RMS } \\
{[\mathbf{m m} / \mathbf{s}]}\end{array}$ & comment \\
\hline 1 & bus & to Prague & 11.47 & 0.0475 & \\
\hline 2 & lorry & to Prague & 12.02 & 0.0099 & \\
\hline 3 & bus & from Prague & 12.57 & 0.0245 & \\
\hline 4 & lorry twice & to Prague & 12.66 & 0.0118 & two vehicles over \\
\hline 5 & $\begin{array}{c}\text { lorry }+ \\
\text { bus }\end{array}$ & $\begin{array}{c}\text { from Prague } \\
\text { to Prague }\end{array}$ & 12.33 & 0.0277 & two vehicles against each \\
\hline 6 & $\begin{array}{c}\text { bus }+ \\
\text { lorry }\end{array}$ & from Prague & 12.57 & 0.0307 & $\begin{array}{c}\text { from Prague bus + from Prague } \\
\text { lorry }\end{array}$ \\
\hline
\end{tabular}

Table 2. Basilica of the Assumption of the Virgin Mary.

\begin{tabular}{|c|c|c|c|c|l|}
\hline Measurement & load & ride direction & $\begin{array}{c}\text { Dominant } \\
\text { frequency }[\mathbf{H z}]\end{array}$ & $\begin{array}{l}\text { RMS } \\
{[\mathbf{m m} / \mathbf{s}]}\end{array}$ & \multicolumn{1}{|c|}{ comment } \\
\hline 1 & bus & to Prague & 12.81 & 0.0119 & $\begin{array}{l}\text { max RMS is in the Y } \\
\text { direction }\end{array}$ \\
\hline 2 & bus & to Prague & 16.60 & 0.0081 & $\begin{array}{l}\text { max RMS is in the Y } \\
\text { direction }\end{array}$ \\
\hline 3 & lorry & to Prague & 10.49 & 0.0089 & $\begin{array}{l}\text { max RMS is in the Y } \\
\text { direction }\end{array}$ \\
\hline 4 & lorry & to Prague & 12.94 & 0.0177 & \\
\hline 5 & lorry & to Prague & 10.01 & 0.0148 & $\begin{array}{l}\text { RMS REF. X is } 0.0069 \mathrm{~mm} / \mathrm{s} \\
\text { RMS REF. Y is } 0.0097 \mathrm{~mm} / \mathrm{s}\end{array}$ \\
\hline 6 & lorry & to Prague & 10.74 & 0.0116 & $\begin{array}{l}\text { RMS REF. Y is greater than } \\
\text { in the Z }(0.0092 \mathrm{~mm} / \mathrm{s}) \\
\text { direction }\end{array}$ \\
\hline
\end{tabular}
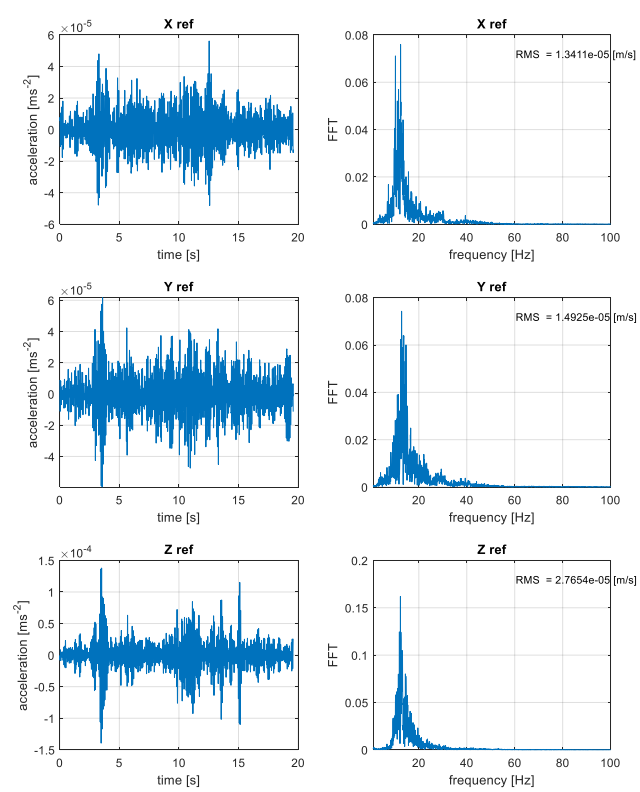

Fig. 4. Lorry traveling to Prague + bus traveling to Prague (the basilica of St Wenceslas).
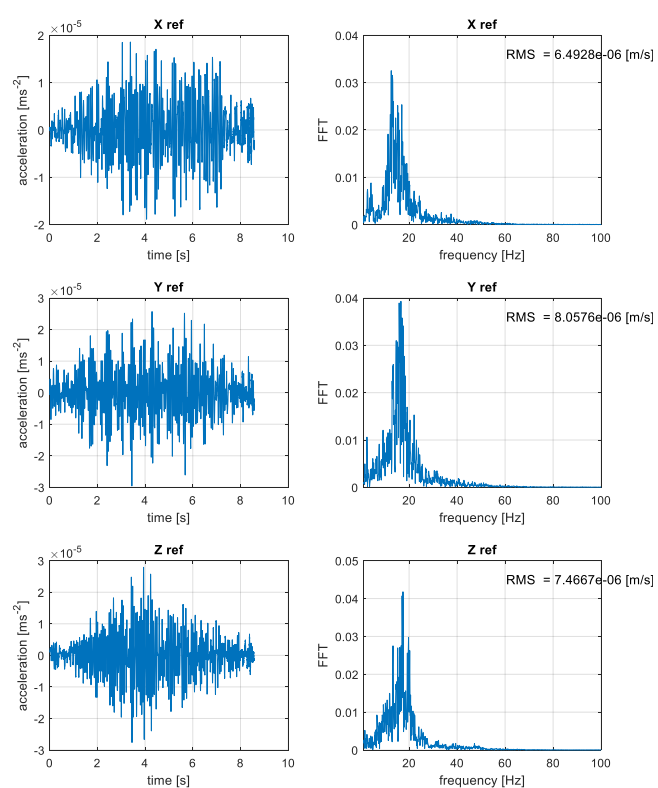

Fig. 5. Bus traveling to Prague. (The Basilica of the Assumption of the Virgin Mary). 


\section{New knowledge of road traffic vibration propagation}

The vertical components of vibrations in the reference position are usually higher than in other positions. This situation does not occur when the reference point is, for example, on the object foundation and the other measured points are on the aboveground parts of the object. When evaluating the responses, it is necessary to consider the complexity of the cathedral structure system, which may include parts showing different natural frequencies and damping. Therefore, measurements in the selected positions in the church may not represent the maximum values of the vibration speed. This also applies to the parts that are in resonance with the excitation frequency (e.g. stained glass, interior equipment, etc.).

\section{Conclusion}

The oldest existing buildings in the Czech Republic are about 1,000 years old. One of the reasons for this great age is the low natural seismicity of our territory and therefore the low threat of earthquakes. This advantage fortunately continues, but technical seismicity, i.e. heavy traffic, manufacturing, underground operations, and demolitions, cause tremors that our historical buildings did not experience in their 'youth'. The existing static forces applied by the buildings' weight or ground pressure are supplemented by dynamic loads. Nevertheless, thanks to acquired experience, Czech engineers have a standard since 1973, unique worldwide, which was revised and supplemented by a subsequent standard in 2019 [16]. It enables an estimation of the safety of buildings exposed to the effects of technical seismicity based on the measured speed of vibrations in a building's foundations. Of course, in the case of historical buildings, further uncertainties affect the parameters of the old masonry during long-term recurrent loads. Therefore, the reliability of such an assessment cannot be considered to be one hundred percent, and thus it is advised that problematic objects be monitored.

The dynamic response induced by the traffic confirmed the same dominant frequency value in the reference point as the other points, regardless of speed, weight and direction of the vehicles. The dominant frequency of response is within the range of 10 to $16 \mathrm{~Hz}$ (St. Mary's Basilica) and within the range of 11 to $12.57 \mathrm{~Hz}$ (St. Wenceslas Basilica); this was also confirmed for other buildings.

It can be stated that article [16] highlights the possibility of broadband response, and it is necessary that even the revised contains this article. In the case of measuring the response only at the site of future foundations (the reference point is in the excavation at the level of the foundation joint) it is necessary to theoretically determine the response at other points.

This study was supported by the grant project DG18P02OVV040 "Monuments in motion", NAKI program II, provided by the Ministry of Culture of the Czech Republic.

\section{References}

1. S. Atamturktur, L. Bornn, F. Hermez, Vibration characteristics of vaulted masonry monuments undergoing differential support settlement, Engineering Structures, 33, 2472-2484 (2011)

2. Bat'a M.: Effect of vibrations generated by passing vehicles buildings as stochastic process. Zeitschrift für Angewandte Mathematic und Mechanik, ZAMM 51, T 76-T80. Berlin, Akademie-verlang (1971)

3. A. Bayraktar, T. Türker, B. Sevım, A. C. Altunişik, F. Yildirim, Modal parameter identification of Hagia Sophia bell tower via ambient vibration test, J. Nondestruct. Eval. 28, 37-47 (2009) 
4. L. Binda, A. Anzani, G. Mirabella Roberti, The failure of ancient Towers: problems for their safety assessment. In: Proceedings of the 4th International Conference on Structural Studies, Repairs and Maintenance of Heritage Architecture, STREMAH 95, Crete: Chania, 179-186 (1995)

5. L. Binda, G. Gatti, G. Mangano, C. Poggi, G. Sacchi Landriani, The collapse of the Civic Tower of Pavia: a survey of the materials and structure. Masonry Int 1992, 20(6),11-20 (1992)

6. A. Brenchich, D. Sabia, Experimental identification of a multi-span masonry bridge: The Tanaro bridge, Constr. Build. Mater. 22, 2087-2099 (2008)

7. S. Casciati, R. Al-Saleh, Dynamic behavior of a masonry civic belfry under operational conditions, Acta Mech. 215, 211-224 (2010)

8. M. S. Chiorino, R. Ceravolo, A. Spadafor, L. Zanotti Fragonara, Abbiati G. Dynamic characterization of complex masonry structures: the Sanctuary of Vicoforte, Int. J. Archit. Herit. 5, 296-314 (2011)

9. M. Crispino, M. D'Apuzzo, Measurement and prediction of traffic-induced vibrations in a heritage building, J. Sound Vib. 246 (2), 319-335 (2001)

10. X. He, C. Jianguo, W. Pengbo, X. Chaoyi, G. De Roeck, G. Degrande, Experimental investigation of railway train-induced vibrations of surrounding ground and a nearby multi-story building, Earthquake Eng. Eng. Vib. 8, 137-148 (2009)

11. O. Hunaidi, M. Tremblay, Traffic-induced building vibrations in Montreal, Canadian Journal of Civil Engineering, 24, 736-753 (1997)

12. M. Ma, V. Markine, W. Liu, Y. Yuan, F. Zhang, Metro train-induced vibrations on historic buildings in Chengdu, China, J. Zhejiang Univ-SC A 12 (10), 782-793 (2011)

13. G. R. Watts, Case studies of the effects of traffic induced vibrations on heritage buildings, Transport and Road Research Laboratory (Crowthorne) 156 (1988) 207 (1989) 246 (1990)

14. F. Magalhães, Á. Cunha, Explaining operational modal analysis with data from an arch bridge, Mech. Syst. Signal Process. 25, 1431-1450 (2011)

15. L. F. Ramos, L. Marques, P. B. Lourenço, G. De Roeck, A. Campos-Costa, J. Roque, Monitoring historical masonry structures with operational modal analysis: two case studies, Mech. Syst. Signal Process. 24, 1291-1305 (2010)

16. ČSN 730040. Loads on structures by technical seismicity and their response (2019)

17. ISO 4866. Mechanical vibration and shock vibration of buildings, Guidelines for the measurement of vibrations and evaluation of their effects on buildings (2010) 